\title{
Assessment of Surgical Staff Perspective toward Hospital Acquired Infection at Selected Pediatric Surgical Units, Saudi Arabia
}

\author{
Manal Amer ${ }^{1}$, Dr. Tamer Mohammed Ali Mahjari ${ }^{2}$, Dr. Osama Anis A. Jamal ${ }^{3}$ \\ ${ }^{1}$ Assistant Professor, Cairo University, Al-Farabi College Jeddah \\ ${ }^{2}$ General Practitioner, King Abdulaziz Hospital, Makkah \\ ${ }^{3}$ General Practitioner, OHUD Hospital, Saudi Arabia
}

\begin{abstract}
Hospital Acquired Infection (HAII) is one of the frequently widespread infections affecting the elderly patients. The aim of this article was to assess surgical staff Perspective toward Hospital Acquired Infection at Selected Pediatric Surgical Units, Saudi Arabia.
\end{abstract}

Keywords: HAI, knowledge and practice

\section{Methods}

A descriptive research design was utilized in the current research. A total of 250 surgical staff at selected surgical units was given a structured questionnaire On August, 2016. They were asked to indicate their Perspective toward Hospital Acquired Infection at Selected Pediatric Surgical Units, Saudi Arabia.

\section{Results}

The current research study objectives were to assess the surgical staff perspective toward methods of transmission of the UTI.Mean knowledge about of items pertaining to surgical staff Perspective toward Hospital Acquired Infection at Selected Pediatric Surgical Units, Saudi Arabia was $(82.3 \%)$.

\section{Conclusions}

Concerning the surgical staff Perspective toward Hospital Acquired Infection at Selected Pediatric Surgical Units, Saudi Arabia, the data findings showed that; there was a highest level of surgical staff Perspective toward Hospital

\section{Introduction}

Currently, Hospital Acquired Infection (HAI) is a major health problem today. It has received the attention of the Government of India and thus the Rao committee, (1968) and the Sharad Kumar Committees in (1976) were set up to investigate the problem of hospital infections in depth. Although it is difficult to assess the exact incidence of hospital acquired infections in our hospitals, ample evidence exists to indicate the magnitude of HAI and related problems.

According to Sharad Kumar's ,(2004), the majority often it is observed that the patient comes to the hospital for treatment of a particular ailment but has acquired infection prolonging his hospital stay sometimes leading to septicemia, multi system organ failure and death. HAI not only prolongs the hospital stay of patients but also increases bed occupancy and therefore puts extra burden on already strained hospital resources.

However, HAI cannot be eradicated entirely because of the fact that whenever more than one patient is taken care of in one place, they are vulnerable to catch infections from each other. A well organized infection control strategies can prevent $25-50 \%$ of HAI as stated by the "Hospital Infection Society of India". The literature also reveals that patients in high dependency areas such as intensive care units (ICUs) are 5-10 times more likely to acquire HAI because of their compromised defense mechanisms. (Bowell, 2011).

Hospital Acquired Infection (HAI) are not only the problem of the patients but also patient's families, hospital staff and the community. Thus hospital acquired infection control is of prime importance in any hospital offering comprehensive health care. Surgeons being in direct contact with the patients round the clock and performing various nursing procedures and assisting physicians and surgeons in various procedures, play an important role in preventing and controlling HAI. Therefore, the need for a high degree of awareness, knowledge and skill in nursing practice is essential to prevent hospital acquired infections. Hence, it was felt that there is a need to assess the existing knowledge and practice of surgical staff towards infection control measures at AIIMS hospital (tertiary care teaching hospital) with a view to identify the areas of knowledge and practice deficit and to strengthen those areas by establishing appropriate measures. Rao's , (2009).

\section{Methods}

A descriptive research design was utilized in the current research. A total of 250 surgical staff of selected surgical units, Saudi Arabia, were given a structured questionnaire during August 2016. This number constitute, over two third of the surgical staff of the time of data collection. All wards

\section{Volume 6 Issue 1, January 2017}




\section{International Journal of Science and Research (IJSR) \\ ISSN (Online): 2319-7064}

Index Copernicus Value (2015): 78.96 | Impact Factor (2015): 6.391

representing units concerning all the subspecialties' were consider as a setting for the current research. The surgical staff at each unit was contacted to discuss the importance of the research and the study protocol. An anonymous 15 -items questionnaire was adopted from valid \& reliable tool .

The questionnaire was pilot-tested and dealt with the following topics: demographic data; data concerning knowledge about of items pertaining to surgical staff Perspective toward Hospital Acquired Infection(HAI). Descriptive statistics like percentage was used to describe the findings using SPSS 20. All categories data were analyzed using the Chi-squared test with or without Yates' correction; Statistical significance for all analyses was presumed for $\mathrm{P}$ at 0.05 .

\section{Results}

The current research study objectives were to assess the surgical staff perspective toward methods of transmission of the UTI. Mean knowledge about of items pertaining to surgical staff Perspective toward Hospital Acquired Infection at Selected Pediatric Surgical Units, Saudi Arabia was $(82.3 \%)$

Regarding the surgical staff knowledge toward the knowledge about of items pertaining to surgical staff Perspective toward Hospital Acquired Infection, controlled by the study setting, the data findings showed that; there was a highest level of knowledge about of items pertaining to surgical staff Perspective toward Hospital Acquired Infection (HAI) within the selected setting.

Table 1: Frequency and percentage of response to items pertaining to surgical staff Perspective toward Hospital Acquired Infection at Selected Pediatric Surgical Units, Saudi Arabia

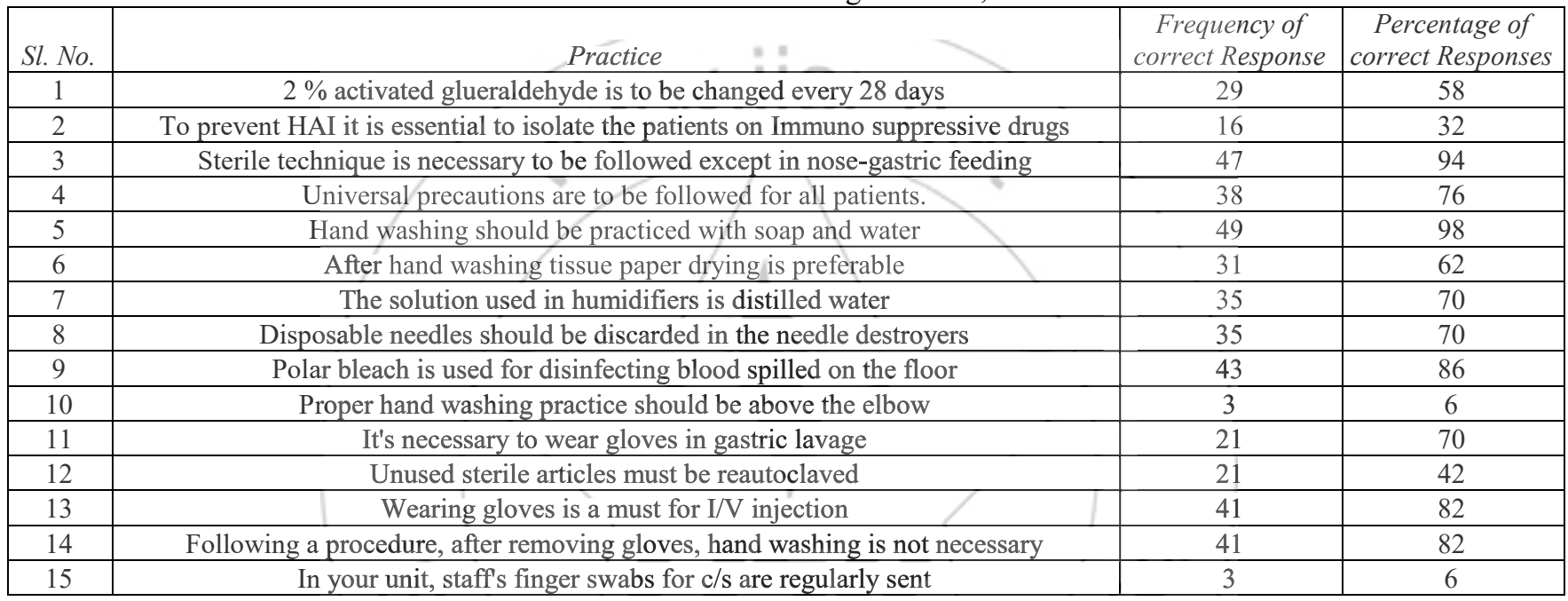

\section{Discussion}

The response rate to the current research was tremendous suggesting that this was an area of significance for surgical staff in selected pediatric surgical units. In this research, more than eighty percent of the surgical staff were replied that there was a high level of knowledge about of items pertaining to surgical staff Perspective toward Hospital Acquired Infection (HAI), this study findings is consistent with the results of the study conducted by Ortona, (2009) ,who studied the factors in aviation of the surgical staff competency in relation to perspectives mean practice regarding measures was( $79.2 \%)$.

Furthermore, the current study data is congruent with the study conducted by Gardiner, A. et al (2004), in which In study of investigation of the staff perspective towards it was found that Frequency and percentage of response to items pertaining to practice on infection control measures. This indicates that there exists a linear relation (correlation) between knowledge and practice. Though the mean knowledge of staff nurses regarding infection control measures is $73.1 \%$, and the mean practice is $62.27 \%$ it is imperative that to attain highest standard of infection control practices which would in turn lead to a reduction in the incidence of hospital acquired infection depends greatly on the level of knowledge.

The current research findings is consistent with the data reported by The average score about the knowledge of disinfection, isolation and nosocomial infection among 374 medical workers was 70.61 , there were $22.10 \%$ below 60 scores and $31.00 \%$ up 80 , there were statistically significant differences among the village, the town and the county medical institutions(P0.05).The average score of the hospitals managing the disinfection, isolation and nosocomial infection in the 31 villages and 11 towns was 29.The laboratory results were not well but the skin liquid disinfectant and the aseptic packets were qualified(100.00\%). The total results found that the score rate between $70 \%$ and $90 \%$ was in the 31 villages and between $50 \%$ and $60 \%$ in the 11 towns.

The current study data is congruent with the study conducted by Orozco , (2007), who found that the average score about the knowledge of disinfection, isolation and nosocomial infection among 374 medical workers was 70.61, there were $22.10 \%$ below 60 scores and $31.00 \%$ up 80, there were statistically significant differences among the village, the town and the county medical institutions(P0.05).The average score of the hospitals managing the disinfection, isolation 


\section{International Journal of Science and Research (IJSR) \\ ISSN (Online): 2319-7064 \\ Index Copernicus Value (2015): 78.96 | Impact Factor (2015): 6.391}

and nosocomial infection in the 31 villages and 11 towns was 29.The laboratory results were not well but the skin liquid disinfectant and the aseptic packets were qualified(100.00\%). The total results found that the score rate between $70 \%$ and $90 \%$ was in the 31 villages and between $50 \%$ and $60 \%$ in the 11 towns.

On the basis of the above study and findings, it can be said that there exists a positive relationship between knowledge and practice. Both are directly proportional to each other. This indicates that with improved knowledge, we can also improve the practice, which should be of major concern in the present day health care scenario.

Finally, Acquired Infection within the study setting. It is more important that the grass-roots surgical staff must pay more attention to prevent and control the nosocomial infection, and to study about the knowledge of disinfection, isolation and nosocomial infection, which should be one of important contents in the management of nosocomial infection.

\section{Conclusions}

The current research aimed to assess the surgical staff knowledge towards the methods of transmission of the UTI. On the basis of the above study and findings, it can be said that there exists a positive relationship between knowledge and practice. Both are directly proportional to each other. This indicates that with improved knowledge, we can also improve the practice, which should be of major concern in the present day health care scenario.

In service education, refresher courses and training programs on infection control measures should be systematically planned and regularly conducted for staff nurses so as to keep staff nurses up to date on the topic.

Continuous surveillance of HAI in vulnerable areas and notification to the concerned authorities is essential and the formulation of regulations should be effectively performed, so as to be able to take appropriate measures in time. Continuous vigilance, assessment and supervision of clinical performance of various levels of workers will help to start a multidimensional attack on the problem of HAI.

\section{Acknowledgements}

Thanks to all the interns helps in conducting the current research

\section{References}

[1] Rao's (2009): Report of the Review committee on Delhi hospitals. New Delhi. Government of India Press.

[2] Sharad Kumar's (2004): Report of the group on hospital infections, Delhi.

[3] Beaumont, E. (1997), Technology Score Care. Focus on Infection Control, American Journal of Nursing. 97 (12), 51.54.

[4] Bowell, B. (2011). Protecting the patient at risk, Nursing times 88 (3), 32-35.
[5] Gardiner, A. et al (2003) Knowledge of disinfection and Motivation, Infection Control Supplement, Nursing Times 91 (20), 59-66

[6] Gould, D.J. (1994), The Significance of Hand drying in the prevention of infection, Nursing Times, 90 (47), 3335 .

[7] Lawrence, Thomson, H et al (1992), Hard - surface disinfectants, Infection Control Supplement, Nursing Times 88 (34), 63-70.

[8] Hawker- Jl, A survey of the implementation of health services guidelines an arrangements of infection controls in health trusts in the West Midlands. DisPublic-Health 1999 Jan; 2 (1):54-8.

[9] Ortona, L (2009), A study on the incidence of post operative infections and surgical sepsis in a university hospital, Infection Control Journal 8 (8), 320-324.

[10] Rostein, C et al (2011) Nosocomial infection rates at an oncology centre, Infection Control and Hospital Eqidemology 16(3), 141-147.

[11] Ward, Courtenay M. et al (1997), Auditing infection. Infection Control Supplement, Nursing Times 93 (29), 71-78.

[12] Westerdahl E, Lindmark B, Eriksson T, et al. Deepbreathing exercises reduce atelectasis and improve pulmonary function after coronary artery bypass surgery. Chest. 2005;128:3482-8. [PubMed].

[13] Mackay MR, Ellis E, Johnston C. Randomised clinical trial of physiotherapy after open abdominal surgery in high risk patients. Aust J Physiother. 2005;51:151-9. [PubMed]

[14] Craven DE, Kunches LM, Kilinsky V, et al. Risk factors for pneumonia and fatality in patients receiving continuous mechanical ventilation. Am Rev Respir Dis. 1986;133:792-6. [PubMed].

[15]Kollef MH. Ventilator-associated pneumonia. A multivariate analysis. JAMA. 1993;270:1965-70. [PubMed].

[16] Kollef MH. The identification of ICU-specific outcome predictors: a comparison of surgical, surgical, and cardiothoracic ICUs from a single institution. Heart Lung. 1995;24:60-6. [PubMed].

[17] Torres A, Serra-Batlles J, Ros E, et al. Pulmonary aspiration of gastric contents in patients receiving mechanical ventilation: The effect of body position. Ann Intern Med. 1992;116:540-3. [PubMed].

[18] Orozco-Levi M, Torres A, Ferrer M, et al. Semirecumbent position protects from pulmonary aspiration but not completely from gastroesophageal reflux in mechanically ventilated patients. Am J Respir Crit Care Med. 2007;152:1387-90. [PubMed] 